\title{
Sedentary time and its association with risk of cardiovascular diseases in adults: an updated systematic review and meta-analysis of observational studies
}

\author{
Wu Jingjie ${ }^{1}$, Lili Yang $^{2 *}$, Ye Jing ${ }^{1}$, Lulu Ran ${ }^{1}, X_{\text {X Yiqing }}^{3}$ and Na Zhou ${ }^{4}$
}

\begin{abstract}
Background: Epidemiological studies assessing the association between sedentary time and cardiovascular diseases (CVD) risks have been published at a rapid pace in recent years, which makes the periodic review of knowledge essential. Furthermore, much of the early and ongoing work used screen time as a marker of total sedentary time, which may weaken the association between sedentary time and CVD risks.

Objective: To update evidence on CVD risks associated with different types of sedentary time, especially total sedentary time and screen time, and to explore as a marker of total sedentary time, whether screen time had similar CVD risks with total sedentary time.

Methods: PRISMA guideline was followed for the performing and reporting of this systematic review and meta-analysis. Three independent researchers searched eight electronic databases and two clinical trial registries for all studies published between January 2015 and December 2021 that assessed the association between sedentary time and CVD risks in adults. A standardized form was used for data extraction and collection. Wilmot and colleagues' modified tool was used for quality assessment. The categorical association was assessed by comparing the pooled effect sizes for CVD risks associated with the highest and the lowest sedentary time categories across included studies. Stata 16.0 and Review Manager 5.3 were used for all statistical analyses, $P \leq 0.05$ was considered as statistically significant.
\end{abstract}

Results: Seventeen prospective cohort studies and two cross-sectional studies with 145,1730 participants and over 48,668 CVD cases and deaths were included. Two included studies measured sedentary time with the accelerometer, 16 studies with self-reported questions, and one study with both the accelerometer and self-reported questions. CVD outcomes were self-reported in two included studies and objectively adjudicated through medical records or death certifications in 17 studies. Compared with the lowest total sedentary time category (median duration, $2.75 \mathrm{~h} / \mathrm{d}$ ), participants in the highest category (median duration, $10.5 \mathrm{~h} / \mathrm{d}$ ) had an increased risk of CVD morbidity (pooled RR, 1.24; $95 \% \mathrm{Cl}, 1.21-1.27)$. Compared with the lowest total sedentary time category (median duration, $2.98 \mathrm{~h} / \mathrm{d}$ ), participants in the highest category (median duration, 10.2 h/d) had an increased risk of CVD mortality (pooled HR, 1.29; 95\% Cl, 1.13-1.47). The association between screen time and CVD risks was similar to total sedentary time with the cut-off

\footnotetext{
*Correspondence: 3200006@zju.edu.cn

${ }^{2}$ Nursing Department, The Fourth Affiliated Hospital, Zhejiang University,

School of Medicine, N1 of Shangcheng Avenue, Yiwu, Zhejiang Province,

China

Full list of author information is available at the end of the article
}

(C) The Author(s) 2022. Open Access This article is licensed under a Creative Commons Attribution 4.0 International License, which permits use, sharing, adaptation, distribution and reproduction in any medium or format, as long as you give appropriate credit to the original author(s) and the source, provide a link to the Creative Commons licence, and indicate if changes were made. The images or other third party material in this article are included in the article's Creative Commons licence, unless indicated otherwise in a credit line to the material. If material is not included in the article's Creative Commons licence and your intended use is not permitted by statutory regulation or exceeds the permitted use, you will need to obtain permission directly from the copyright holder. To view a copy of this licence, visit http://creativecommons.org/licenses/by/4.0/. The Creative Commons Public Domain Dedication waiver (http://creativeco mmons.org/publicdomain/zero/1.0/) applies to the data made available in this article, unless otherwise stated in a credit line to the data. 
point of $5-6 \mathrm{~h} / \mathrm{d}$. The associations between occupational sitting time, leisure sedentary time, and CVD risks stayed inconclusive.

Conclusion: Total sedentary time and screen time are both associated with cardiovascular health. As a marker of total sedentary time, screen time over 5-6 h/d had similar CVD risks with total sedentary time over 10-11 h/d.

Keywords: Sedentary time, Screen time, Cardiovascular diseases, Morbidity, Mortality, Systematic review, Metaanalysis

\section{Introduction}

Cardiovascular diseases (CVD) are the leading cause of death globally, taking an estimated 17.9 million lives each year $[1,2]$. Physical inactivity is a well-known and modifiable risk factor for CVD. Insufficient moderate-to-vigorous physical activity and prolonged sedentary behavior are two independent facets of physical inactivity. Current guidelines regard exercise as a cornerstone in maintaining and improving cardiovascular health and recommend at least $150 \mathrm{~min}$ of moderate physical activity or $75 \mathrm{~min}$ of vigorous physical activity per week to reduce the CVD risks $[3,4]$. Despite these recommendations, more than half of adults do not meet the minimum volume of physical activity based on the data from the Chinese National Center for Cardiovascular Diseases and the American College of Cardiology [2, 3]. For older people and people with physical disabilities, meeting these recommendations can be particularly burdensome or even impossible. Thus, as another facet of physical inactivity, more attention should be paid to sedentary behavior and its preventive interventions, especially for people who spend most of their waking time sedentarily and cannot meet the recommended level of physical activity.

Sedentary behavior is defined as any waking behavior characterized by an energy expenditure $\leq 1.5$ metabolic equivalents (METs) while in a sitting, reclining or, lying posture [5], and sedentary time is the time spent in sedentary behavior. A dose-response meta-analysis published in 2016, including 72,0425 participants and 25,769 CVD cases and deaths, found a nonlinear association between total sedentary time and risk of CVD in continuous analysis, with a statistically significant increased risk observed only at a total sedentary time of more than $10.04 \mathrm{~h} / \mathrm{d}$ [6]. In recent years, epidemiological studies assessing the association between sedentary time and CVD risks have been published at a rapid pace, especially prospective cohort studies with large sample sizes and long follow-up durations, which makes the periodic review of knowledge essential. Furthermore, much of the early and ongoing work in this area used screen time as a marker of total sedentary time [7]. Since sitting in front of electronic screens is one of the sedentary behavior types, representing screen time as a marker of total sedentary time may weaken the association between total sedentary time and CVD risks. However, to the best of our knowledge, there is no previous study exploring whether screen time is a real marker of total sedentary time, which means having similar CVD risks. To fill these gaps, the primary objective of this study was to update CVD risks associated with different types of sedentary time, especially total sedentary time and screen time. The second objective was to explore as a marker of total sedentary time, whether screen time had similar CVD risks to total sedentary time.

\section{Methods \\ Literature Search Strategy}

The Preferred Reporting Items for Systematic reviews and Meta-Analyses (PRISMA) guidelines was followed for the performing and reporting of this present systematic review and meta-analysis (Supplementary File 1) [8, 10]. We searched for all observational studies including prospective cohort studies, retrospective case-control studies, and cross-sectional studies, that assessed the association between sedentary time and CVD risks among adults (over 18 years old at baseline). Systematic searches through eight electronic databases including PubMed, Embase, Cochrane Library, Web of Science, China National Knowledge Infrastructure, Wanfang, Weipu, and SinoMed, and two clinical trial registries including Clinical trials and China Clinical Trial Registry, were performed with the limitation of publication date between January 2015 and December 2021. We used various combinations of the following keywords and $\mathrm{MeSH}$ terms: sedentary behavior, sedentary lifestyle, screen time, television, computers, video games, occupational sitting, cardiovascular diseases, coronary disease, stroke, mortality, morbidity, risk factors, et al. Detailed search terms are shown in Supplementary File 2 (Table S1). Reference lists of the included studies and relevant reviews were also manually searched.

\section{Study Selection}

The primary exposure indicator of interest in this study was total sedentary time, defined as total waking hours per day that have low energy expenditure and are often performed in a sitting or reclining posture. The secondary exposure indicator was screen time, defined as total 
waking hours per day that are in front of an electronic screen, such as watching TV, using personal computers in leisure time, or playing video games, considering that as a marker of total sedentary time, it has been demonstrated to be associated with CVD risks in population cohort studies [7, 9, 11]. Additional exposure indicators such as occupational sitting time and leisure sedentary time were considered tertiary. The primary outcome in this study was CVD risks (morbidity or mortality), including ischemic heart diseases (IHD), coronary heart diseases (CHD), stroke, heart failure and CVD-related death. Because several original studies' outcome was CVD morbidity and mortality, it was considered as the second outcome.

Observational studies that assessed CVD risks associated with all types of sedentary time were included in the initial study selection process, but only studies that reported total sedentary time or screen time as the main exposure indicator were included in the meta-analysis. Three independent reviewers (JJW, LLR \& JY) performed the initial screening of all titles and abstracts and then evaluated all potentially relevant articles based on the full-text reviews. Studies were excluded if they failed to meet all the criteria mentioned above. Any discrepancies regarding study inclusion were adjudicated by discussion, and if needed, in consultation with the senior author (LLY). If multiple studies used the data of the same sample source, studies with longer follow-up durations, larger sample sizes, and/or more detailed reports of sedentary behavior and physical activity were included.

\section{Quality Assessment}

The study quality was assessed using the methods created by Wilmot and colleagues [10], which had similar elements with Newcastle-Ottawa Scale but were modified to assess studies that explore sedentary time with associated risks for health problems. The total score of this quality assessment tool was 6 ( 1 for a prospective study design; if sedentary time was self-reported, 1 for reported reliability, 1 for reported validity, 2 if an objective measurement of sedentary time was used; 1 if two or more covariates were adjusted for; 1 if physical activity was adjusted for; 1 for an objective measurement of CVD outcomes, such as medical records and death certifications). A score of 5 or 6 was considered as high quality, 3 or 4 moderate quality, and 0 or 2 poor quality. Studies attaining poor quality were excluded from this study.

\section{Data Collection}

Three independent reviewers (JJW, LLR \& JY) independently performed the data collection using a standardized form including publication information (first author's family name and publication year), country, sample source, study design, follow-up duration, sample characteristics (size, age, and proportion of male), types, definitions and measurements of sedentary time, physical activity and CVD outcomes, the number of cases, odds ratio (OR), hazard risk (HR), relative risk (RR) and confidence interval $(\mathrm{CI})$ extracted from the most adjusted models and covariates that entered the most adjusted models. Any discrepancies regarding extracted data were resolved by discussion, and if needed, in consultation with the senior author (LLY).

\section{Statistical analysis \\ Exposure Assessment}

For studies that assessed categorical associations between sedentary time and risk of CVD, all of them reported quantitative estimates as average duration or time range. The average duration for each category was used to define the median sedentary time for that category. If a time range was reported for a sedentary time category without the average duration, we estimated the approximate median sedentary time using the midpoints of the lower and upper boundaries. For studies with an open-ended highest sedentary time category, we assumed that this category had the same amplitude as the closet category. For studies with an open-ended lowest sedentary time category, we assumed that the lower boundaries of this category were $0 \mathrm{~h} / \mathrm{d}$. As for studies that assessed the continuous association between sedentary time and risk of CVD, and reported effect size as each additional hour of sedentary time, we assumed that the reference category was $1 \mathrm{~h} / \mathrm{d}$, and the other category was $2 \mathrm{~h} / \mathrm{d}$. The reported time and estimated median of each sedentary time category are detailed in Supplementary File 2 (Table S2).

\section{Outcome Assessment}

We extracted HRs and 95\% CIs from the Cox proportional hazard regression models and extracted RRs and 95\% CIs from the logistic regression models. All these models had the most complete adjustment for other CVD risk factors. Where RR and 95\% CI were not given, a formula from Zhang and $\mathrm{Yu}$ was used to correct the most adjusted $\mathrm{OR}\left(R R=\frac{O R}{(1-P 0)+(P 0 \times O R)}, \mathrm{P} 0\right.$ indicates the incidence of the outcome in the non-exposed group) [12]. We considered HRs to be closely equal to RRs and used RRs to assess the association between sedentary time and CVD risks.

\section{Categorical Analysis}

Because most of the included studies had two or more sedentary time categories, we used a previously described approach to pool data across studies and generated two pooled categories of sedentary time (the highest and the lowest) as described in Table 2 [6]. The pooled RRs and 
95\% CIs for CVD risks associated with different types and categories of sedentary time were calculated by comparing the highest with the lowest categories. Heterogeneity of RRs and 95\% CIs across studies was tested by using the $I^{2}$ statistics at the $P<0.10$ level of significance, when $I^{2} \leq 50 \%$ and $P>0.10$, Inverse-Variance fixed-effect model was used to pool the RRs and 95\% CIs, whereas DerSimonian and Laird random-effect model was used. Sensitivity analysis was further performed to examine the influence of various exclusion criteria on the overall risk estimate. Publication bias was assessed by Egger's and Begg's tests. Sensitivity analysis and part of publication bias were performed using Stata 16.0. Other analyses were performed using Review Manager version 5.3. Statistical analyses were declared significant for a two-sided $P \leq 0.05$.

\section{Results}

\section{Search Results and Study Characteristics}

The study selection process and results are shown in Supplementary File 2 (Fig. S1). Briefly, 6813 studies were identified through searching the electronic databases and clinical trial registries, and two studies were added through hand-searching from reference lists of the included studies. A study reporting an inappropriate OR value of 176.62 (95\% CI: 43.33-719.90) was identified as an outlier and excluded after discussion. Finally, inclusion criteria were met in 19 studies [7, 9, 11, 13-28], including 17 prospective studies and two cross-sectional studies with 145,1730 unique participants and over 48,668 unique CVD cases and deaths. Baseline characteristics of the included studies are shown in Table 1. Of the 19 included studies, six were from America, five were from Europe, and four each from Asia and Australia. One study included only women and 18 studies included men and women. Nine studies' exposure indicator was total sedentary time (or total sitting time), nine studies were screen time including time spent in television watching, computer using in leisure time and video gaming, two studies were occupational sitting time, and one study was leisure sedentary time. Seven studies' outcome was CVD morbidity, nine was CVD mortality, and four was CVD morbidity and mortality. Total sedentary time was assessed with self-reported questions in five studies and assessed with the accelerometer in three studies. Screen time, occupational sitting time, and leisure sedentary time were all assessed with self-reported questions. CVD outcomes were adjudicated by self-report in two studies, and by medical records or death certifications came from the administrative database and/or national mortality index in 17 studies (Supplementary File 2, Table S4). Most studies adjusted for covariates such as age $(n=17)$, sex $(n=17)$, physical activity $(n=17)$ and smoking
( $n=17)$ in the most adjusted model (Supplementary File 2, Table S3a, S3b, S3c). Assessment of study quality yielded an average score of 4.79 , and a median score of 5 (Supplementary File 2, Table S5). The main reasons for not scoring were as follows: (i) the self-reported questions used to measure sedentary time without a reliability or validity test; (ii) the study design was a cross-sectional study; (iii) physical activity was not included in the most adjusted models as a covariate; and (iv) CVD outcomes were self-reported.

\section{Association Between Total Sedentary Time and CVD risks}

Because Engelen's study (OR, 1.28; 95\% CI, 1.02-1.60) lacked the data needed to correct the most adjusted OR, this cross-sectional study was not included in the metaanalysis. Table 2 showed that there were one prospective study, and one cross-sectional study entered the metaanalysis to assess the association between total sedentary time and CVD morbidity. Compared with the lowest total sedentary time category (median duration, $2.75 \mathrm{~h} / \mathrm{d}$ ), participants in the highest total sedentary time category (median duration, $10.5 \mathrm{~h} / \mathrm{d}$ ) had an increased risk of CVD morbidity (pooled RR, 1.24; 95\% CI, 1.21-1.27). No significant heterogeneity was observed in the pooled analysis across studies $\left(I^{2}=0 \%, P=0.42\right)$. Because only two studies were included in this subgroup of meta-analysis, publication bias tests and sensitivity analysis were not suitable.

There were four prospective studies entered in the meta-analysis to assess the association between total sedentary time and CVD mortality. Participants in the highest total sedentary time category (median duration, $10.2 \mathrm{~h} / \mathrm{d}$ ) had an increased risk of CVD-related death (pooled HR, 1.29; 95\% CI, 1.13-1.47) when compared with the lowest total sedentary time category (median duration, $2.98 \mathrm{~h} / \mathrm{d}$ ). No significant heterogeneity or significant publication bias was observed in the pooled analysis across studies $\left(I^{2}=35 \%, P=0.20 ; P\right.$ for Egger line regression test $=0.144 ; P$ for Begg rank correlation test $=0.308$ ). For sensitivity analysis, the exclusion of any single study did not materially change the overall risk estimates.

There were also three prospective studies that assessed total sedentary time with CVD morbidity and mortality. Compared with the lowest total sedentary time category (median duration, $1 \mathrm{~h} / \mathrm{d}$ ), participants in the highest total sedentary time category (median duration, $5 \mathrm{~h} / \mathrm{d}$ ) had an increased risk of CVD morbidity and mortality (pooled HR, 1.29; 95\% CI, 0.93-1.80). However, this association was not statistically significant $(P=0.13)$. Moderate heterogeneity was observed in the pooled analysis across studies $\left(I^{2}=69 \%, P=0.04\right)$. No significant publication bias was observed $(P$ for Egger line regression 


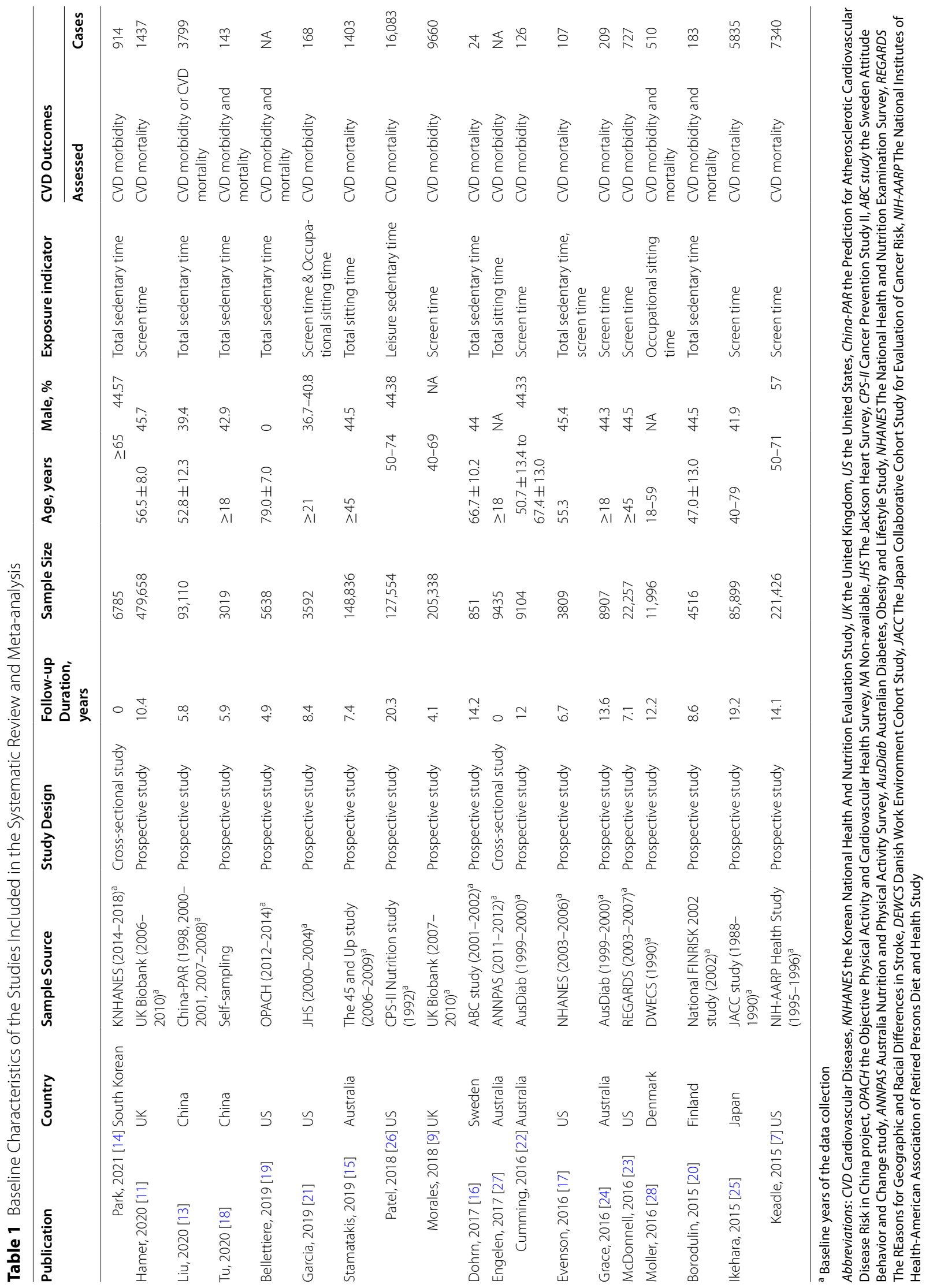


Table 2 Pooled Association Between Highest versus Lowest Sedentary Time Duration and CVD Risks

\begin{tabular}{|c|c|c|c|c|c|}
\hline Type of Sedentary Time & $\begin{array}{l}\text { Median duration of } \\
\text { sedentary time, } h / d\end{array}$ & CVD outcomes & $\begin{array}{l}\text { Pooled HR/ } \\
\text { RR [ }[95 \% \mathrm{Cl}], P \\
\text { value }\end{array}$ & $\begin{array}{l}\text { Heterogeneity } \\
\text { test }\left(I^{2} \text { and } P\right. \\
\text { value })\end{array}$ & Included Studies \\
\hline \multirow[t]{3}{*}{ Total sedentary time } & $\begin{array}{l}\text { Highest: } 10.5 \\
\text { Lowest: } 2.75\end{array}$ & CVD morbidity & $\begin{array}{l}1.24[1.21,1.27] \\
P<0.05\end{array}$ & $P^{2}=0 \%, P=0.42$ & Liu, 2020 [13]; Park 2021 [14] \\
\hline & $\begin{array}{l}\text { Highest: } 10.2 \\
\text { Lowest: } 2.98\end{array}$ & CVD mortality & $\begin{array}{l}1.29[1.13,1.47] \\
P<0.05\end{array}$ & $R^{2}=35 \%, P=0.20$ & $\begin{array}{l}\text { Liu, } 2020 \text { [13]; Stamatakis, } \\
2019 \text { [15]; Dohrn, } 2017 \text { [16]; } \\
\text { Evenson, } 2016 \text { [17] }\end{array}$ \\
\hline & $\begin{array}{l}\text { Highest: } 5 \\
\text { Lowest: } 1\end{array}$ & $\begin{array}{l}\text { CVD morbidity and mortal- } \\
\text { ity }\end{array}$ & $\begin{array}{l}1.29[0.93,1.80] \\
P=0.13\end{array}$ & $P^{2}=69 \%, P=0.04$ & $\begin{array}{l}\text { Tu, } 2020 \text { [18]; Bellettiere, } 2019 \\
\text { [19]; Borodulin, } 2015 \text { [20] }\end{array}$ \\
\hline \multirow[t]{5}{*}{ Screen time } & $\begin{array}{l}\text { Highest: } 3.75 \\
\text { Lowest: } 1\end{array}$ & CVD morbidity & $\begin{array}{l}1.03[0.99,1.07] \\
P=0.21\end{array}$ & $P^{2}=95 \%, P<0.001$ & $\begin{array}{l}\text { Garcia, } 2019 \text { [21]; Morales, } \\
2018 \text { [9]; Cumming, } 2017 \text { [22]; } \\
\text { McDonnell, } 2016 \text { [23] }\end{array}$ \\
\hline & $\begin{array}{l}\text { Highest: } 5 \\
\text { Lowest: } 1\end{array}$ & CVD morbidity ${ }^{a}$ & $\begin{array}{l}1.22[0.98,1.52] \\
P=0.07\end{array}$ & $P^{2}=0 \%, P=0.35$ & $\begin{array}{l}\text { Garcia, } 2019 \text { [21]; McDonnell, } \\
2016 \text { [23] }\end{array}$ \\
\hline & $\begin{array}{l}\text { Highest: } 5 \\
\text { Lowest: } 1\end{array}$ & CVD morbidity ${ }^{b}$ & $\begin{array}{l}1.04[1.03,1.05] \\
P<0.05\end{array}$ & $P^{2}=32 \%, P=0.23$ & $\begin{array}{l}\text { Garcia, } 2019 \text { [21]; Morales, } \\
2018 \text { [9]; McDonnell, } 2016 \text { [23] }\end{array}$ \\
\hline & $\begin{array}{l}\text { Highest: } 5 \\
\text { Lowest: } 1\end{array}$ & CVD mortality & $\begin{array}{l}1.27[1.05,1.52] \\
P=0.01\end{array}$ & $P^{2}=87 \%, P<0.001$ & $\begin{array}{l}\text { Hamer, } 2020 \text { [1 1]; Evenson, } \\
2016 \text { [17]; Grace, } 2016 \text { [24]; } \\
\text { Ikehara, } 2015 \text { [25]; Keadle, } \\
2015 \text { [7] }\end{array}$ \\
\hline & $\begin{array}{l}\text { Highest: } 6 \\
\text { Lowest: } 1\end{array}$ & CVD mortality ${ }^{\mathrm{b}}$ & $\begin{array}{l}1.36[1.03,1.78] \\
P<0.05\end{array}$ & $P^{2}=80 \%, P=0.002$ & $\begin{array}{l}\text { Evenson, } 2016 \text { [17]; Grace, } \\
2016 \text { [24]; Ikehara, } 2015 \text { [25]; } \\
\text { Keadle, } 2015 \text { [7] }\end{array}$ \\
\hline
\end{tabular}

${ }^{a}$ Results of sensitivity analysis

${ }^{\mathrm{b}}$ In these meta-analysis, studies which did not include any physical activity intensity in the most adjusted models as a covariate were excluded

test $=0.182 ; P$ for Begg rank correlation test $=0.296$ ). For sensitivity analysis, the exclusion of any single study did not materially change the overall risk estimates. The forest plots and results of sensitivity analysis are shown in Supplementary File 2 (Fig. S2-S6).

\section{Association Between Screen Time and CVD risks}

Table 2 showed that there were four prospective studies entered the meta-analysis to assess the association between screen time and CVD morbidity. Compared with the lowest screen time category (median duration, $1 \mathrm{~h} / \mathrm{d})$, participants in the highest screen time category (median duration, $3.75 \mathrm{~h} / \mathrm{d}$ ) had an increased risk of CVD (pooled HR, 1.03; 95\% CI, 0.99-1.07). However, this association had no significant difference $(P=0.21)$. High heterogeneity was observed in the pooled analysis across studies $\left(I^{2}=95 \%, P<0.001\right)$. No significant publication bias was observed ( $P$ for Egger line regression test $=0.345 ; P$ for Begg rank correlation test $=0.734$ ). For sensitivity analysis, exclusion of Cumming 2017 and Morales 2018 did materially change the overall risk estimates (pooled HR, 1.22; 95\% CI: $0.98-1.52 ; I^{2}=0 \%$, $P=0.35)$. This association also had no significant difference $(P=0.07)$.

As for the association between screen time and CVD mortality, there were four prospective studies and one cross-sectional study entered in the meta-analysis.
Participants in the highest screen time category (median duration, $5 \mathrm{~h} / \mathrm{d}$ ) had an increased risk of CVD-related death (pooled RR, 1.27; 95\% CI, 1.05-1.52) when compared with the lowest screen time (median duration, $1 \mathrm{~h} / \mathrm{d})$. High heterogeneity was observed in the pooled analysis across studies $\left(I^{2}=87 \%, P<0.001\right)$. No significant publication bias was observed ( $P$ for Egger line regression test $=0.267 ; P$ for Begg rank correlation test $=0.462$ ). For sensitivity analysis, the exclusion of any single study did not materially change the overall risk estimates.

These associations were further strengthened when two studies did not include any physical activity intensity in the most adjusted models as a covariate were excluded (Table 2). The forest plots and results of sensitivity analysis are shown in Supplementary File 2 (Fig. S8-S13).

\section{Association Between Other Types of Sedentary Time and CVD risks}

There were two prospective studies that assessed occupational sitting time with the associated risk of CVD. Garcia found that comparing participants who never or seldom sat during working time, participants often or always sat during the working time had an increased risk of CVD morbidity (HR, 1.06; 95\%CI, 0.73-1.55). Adversely, Moller found that comparing participants who had more than $25 \mathrm{~h} /$ week being seated at work, participants who had less than $25 \mathrm{~h}$ /week being seated at work 
had a decreased risk of CVD morbidity and mortality (HR, 0.94; 95\%CI, 0.71-1.27). Both associations had no significant difference. There was one study that assessed leisure sedentary time with the associated risk of CVD mortality. Patel found that comparing participants who had less than three hours per day being seated during leisure time, participants who had more than six hours per day being seated during leisure time had an increased risk of CHD (HR, 1.26; 95\% CI, 1.17-1.35), stroke (HR, 1.15; 95\%CI, 1.03-1.28) and all CVD (HR, 1.19; 95\%CI, $1.13-1.25)$.

\section{Discussion}

The findings from this systematic review and metaanalysis, based on 14,51,730 participants from 17 prospective studies and two cross-sectional studies and including over 48,668 unique CVD cases and deaths, demonstrated that CVD was significantly associated with more than $10-11 \mathrm{~h} / \mathrm{d}$ of total sedentary time (morbidity, RR, 1.24; 95\% CI, 1.21-1.27; mortality, HR, 1.29; 95\% CI, 1.13-1.47) which is similar with Pandey's dose-response meta-analysis, and significantly associated with more than $5-6 \mathrm{~h} / \mathrm{d}$ of screen time (morbidity, HR, 1.04; $95 \%$ CI, 1.03-1.05; mortality, HR, 1.36; 95\% CI, 1.03-1.78) after adjustment for physical activity and other CVD risks. The differences between the highest and the lowest screen time categories in Cumming's ( 2 vs $1.64 \mathrm{~h} / \mathrm{d}$ ) and Morales's (2.5 vs $1 \mathrm{~h} / \mathrm{d}$ ) study were small, which potentially influenced the effect sizes. Thus, in sensitivity analysis, these two studies were excluded when assessing the association between screen time and CVD morbidity, and the association was further strengthened but became insignificant (HR, 1.22; 95\% CI, 0.98-1.52; $P=0.07$ ). The associations between occupational sitting time, leisure sedentary time, and CVD risks stayed inconclusive due to the small number or conflicting results of the included studies, which need more epidemiology studies to further confirm.

With the technological advances, we spend most of our leisure time being in front of electronic screens, such as television, computer, video, and smartphone. This study found that as a marker of total sedentary time, screen time had similar CVD risks with total sedentary time. Given that not all the included studies adjusted for total sedentary time or other types of sedentary time when assessing the association between screen time and CVD risks except for Garcia's study, the results should be interpreted carefully. The exact mechanisms that explained the pathogenesis between sedentary time and CVD are still unclear and warrant further research, but several possible hypotheses have been proposed by clinical trials and epidemiological studies. The most persuasive hypothesis is that sedentary time increased the production and accumulation of reactive oxygen species, which is correlated with the increased cytokine release and other inflammatory markers, eventually leading to endothelial dysfunction [29-31]. There is evidence that the consumption of energy-dense, nutrient-poor snack foods increases during screen time, and a cross-sectional study from Australia in 2013 demonstrated that screen time and snack food consumption were jointly associated with the metabolic syndrome and its components, this may lead to a higher cardiovascular risk [32].

Our findings have important public health implications. Current guidelines emphasized the cardioprotective role of physical activity, in contrast, there is no guideline targeting sedentary behavior. Thus, it is unclear for adults how many hours per day of sedentary behavior is harmful and how to attenuate, even eliminate the risk caused by prolonged and uninterpreted sedentary behavior. Since adults spend most of their waking hours doing sedentary activities $[13,16]$, the lack of relevant guidelines is an important gap in the public health area. For adults who cannot tolerate more than $150 \mathrm{~min}$ of moderate physical activity or $75 \mathrm{~min}$ of vigorous physical activity per week, avoiding a high volume of sedentary time has particular importance. Sit-stand, treadmill, and bicycle workstations have been designed to interrupt prolonged occupational sitting time and proved as effective and beneficial interventions [33, 34]. However, interventions for adults with prolonged screen time out of work are limited and there is a need for evidence-based interventions to reduce leisure screen time, since that over $5-6 \mathrm{~h} / \mathrm{d}$ of screen time may have similar CVD risks with over $10 \mathrm{~h} / \mathrm{d}$ of total sedentary time.

This systematic review and meta-analysis have several limitations. First, the study protocol was not registered previously. Second, we only included English or Chinese language studies when literature screening, which may lead to publication bias and limit the generalizability of the study. Third, since other CVD risk factors are likely to influence the association between sedentary time and risk of CVD, the discrepancy of covariates included in the most adjusted models may potentially produce bias. Lastly, only three of the included studies measured sedentary time with the objective accelerometer, and many other included studies measured sedentary time with self-reported questions without reported reliability or validity, which may limit the objectivity of the results. However, the large sample sizes and long follow-up durations of our included studies may offset some of these limitations. 


\section{Conclusion}

This systematic review and meta-analysis demonstrated that a total sedentary time of more than $10-11 \mathrm{~h} / \mathrm{d}$ and a screen time of more than $5-6 \mathrm{~h} / \mathrm{d}$ had similar CVD risks after adjustment for physical activity and other CVD risk factors. Future studies are needed to explore the mechanism under sedentary time and CVD risks, and conduct evidence-based interventions to reduce sedentary time, especially screen time.

\section{Supplementary Information}

The online version contains supplementary material available at https://doi. org/10.1186/s12889-022-12728-6.

\section{Additional file 1.}

Additional file 2.

\section{Acknowledgements}

The authors wish to express thanks to Roger Watson for checking and improving the English of this article.

\section{Authors' contributions}

Study design: JJW, LLY, NZ. Literature screening, data extraction \& quality assessment: JJW, JY, LLR, LLY. Statistical analysis: JJW. Manuscript writing: JJW, YQX. Manuscript revision: JJW, LLY, YQX. The author(s) read and approved the final manuscript.

\section{Funding}

This study was supported by Health Commission of Zhejiang Province, China (2022KY843) and Jinhua Science and Technology Bureau, China (2021-3-010).

\section{Availability of data and materials}

All data generated or analyzed during this study are included in this published article and its supplementary file 2 .

\section{Declarations}

Ethics approval and consent to participate

Not applicable.

\section{Consent for publication}

Not applicable.

\section{Competing interests}

Not applicable.

\begin{abstract}
Author details
${ }^{1}$ School of Medicine, Zhejiang University, 268th of Kaixuan Road, Shangcheng District, Hangzhou, Zhejiang Province, China. ${ }^{2}$ Nursing Department, The Fourth Affiliated Hospital, Zhejiang University, School of Medicine, N1 of Shangcheng Avenue, Yiwu, Zhejiang Province, China. ${ }^{3}$ School of Allied health professions, Loma Linda University, 24951 N Circle Drive, Loma Linda, CA 92350, USA. ${ }^{4}$ Sir Run Run Shaw Hospital, School of Medicine, Zhejiang University, 3th of East Qingchun Road, Shangcheng District, Hangzhou, Zhejiang Province, China.
\end{abstract}

Received: 16 May 2021 Accepted: 3 February 2022

Published online: 12 February 2022

\section{References}

1. World Health Organization. Cardiovascular diseases (CVDs), 2017. https:// www.who.int/news-room/fact-sheets/detail/cardiovascular-disea ses-(cvds).

2. National Center for Cardiovascular Diseases. Reports on cardiovascular diseases in China 2018, Encyclopedia of China Publishing House; 2019. p. 2-4. https://www.nccd.org.cn/News/Information/Index/1089

3. Arnett DK, Blumenthal RS, Albert MA, Buroker AB, Goldberger ZD, Hahn EJ, et al. 2019 ACC/AHA Guideline on the Primary Prevention of Cardiovascular Disease: A Report of the American College of Cardiology/ American Heart Association Task Force on Clinical Practice Guidelines. Circulation. 2019;140(11):e596-646. https://doi.org/10.1161/CIR.00000 00000000678 Epub 2019 Mar 17. Erratum in: Circulation. $2019 \mathrm{Sep}$ 10;140(11):e649-e650. Erratum in: Circulation. 2020 Jan 28;141(4):e60. Erratum in: Circulation. 2020 Apr 21;141(16):e774. PMID: 30879355; PMCID: PMC7734661.

4. Ekelund U, Brown WJ, Steene-Johannessen J, Fagerland MW, Owen N, Powell KE, et al. Do the associations of sedentary behaviour with cardiovascular disease mortality and cancer mortality differ by physical activity level? A systematic review and harmonised meta-analysis of data from 850060 participants. Br J Sports Med. 2019;53(14):886-94. https://doi. org/10.1136/bjsports-2017-098963 Epub 2018 Jul 10. PMID: 29991570.

5. Tremblay MS, Aubert S, Barnes JD, Saunders TJ, Carson V, Latimer-Cheung AE, et al. SBRN Terminology Consensus Project Participants. Sedentary time Research Network (SBRN) - Terminology Consensus Project process and outcome. Int J Behav Nutr Phys Act. 2017;14(1):75. https://doi.org/10. 1186/s12966-017-0525-8 PMID: 28599680; PMCID: PMC5466781.

6. Pandey A, Salahuddin U, Garg S, Ayers C, Kulinski J, Anand V, et al. Continuous Dose-Response Association Between Sedentary Time and Risk for Cardiovascular Disease: A Meta-analysis. JAMA Cardiol. 2016;1(5):575-83. https://doi.org/10.1001/jamacardio.2016.1567 PMID: 27434872.

7. Keadle SK, Moore SC, Sampson JN, Xiao Q, Albanes D, Matthews CE. Causes of Death Associated With Prolonged TV Viewing: NIH-AARP Diet and Health Study. Am J Prev Med. 2015;49(6):811-21. https://doi.org/10. 1016/j.amepre.2015.05.023 Epub 2015 Jul 26. PMID: 26215832; PMCID: PMC4656060.

8. Moher D, Liberati A, Tetzlaff J, Altman DG. Preferred reporting items for systematic reviews and meta-analyses: the PRISMA statement. BMJ. 2009;339:b2535. https://doi.org/10.1136/bmj.b2535.

9. Celis-Morales CA, Lyall DM, Steell L, Gray SR, Iliodromiti S, Anderson J, et al. Associations of discretionary screen time with mortality, cardiovascular disease and cancer are attenuated by strength, fitness and physical activity: findings from the UK Biobank study. BMC Med. 2018;16(1):77. https://doi.org/10.1186/s12916-018-1063-1 PMID: 29792209; PMCID: PMC5966877

10. Wilmot EG, Edwardson CL, Achana FA, Davies MJ, Gorely T, Gray LJ, et al. Sedentary time in adults and the association with diabetes, cardiovascular disease and death: systematic review and meta-analysis. Diabetologia. 2012;55(11):2895-905. https://doi.org/10.1007/s00125-012-2677-z Epub 2012 Aug 14. Erratum in: Diabetologia 2013 Apr;56(4):942-3. PMID: 22890 825.

11. Hamer M, Ding D, Chau J, Duncan MJ, Stamatakis E. Association between TV viewing and heart disease mortality: observational study using negative control outcome. J Epidemiol Community Health. 2020;74(4):391-4. https://doi.org/10.1136/jech-2019-212739 Epub 2020 Jan 20. PMID: 31959721.

12. Zhang J, Yu KF. What's the relative risk? A method of correcting the odds ratio in cohort studies of common outcomes. JAMA. 1998;280(19):16901. https://doi.org/10.1001/jama.280.19.1690 PMID: 9832001.

13. Liu Q, Liu F, Li J, Huang K, Yang X, Chen, J.,... Gu, D. sedentary time and risk of incident cardiovascular disease among Chinese adults. Sci Bull. 2020;65(20):1760-6. https://doi.org/10.1016/j.scib.2020.05.029.

14. Park S, Nam JY. The Impact of sedentary time and Self-Rated Health on Cardiovascular Disease and Cancer among South Korean Elderly Persons Using the Korea National Health and Nutrition Examination Survey (KNHANES) 2014-2018 Data. Int J Environ Res Public Health. 2021;18(14):7426. https://doi.org/10.3390/ijerph18147426 PMID: 34299877; PMCID: PMC8305062.

15. Stamatakis E, Gale J, Bauman A, Ekelund U, Hamer, M.... Ding, D. Sitting Time, Physical Activity, and Risk of Mortality in Adults. J Am Coll Cardiol. 2019;73(16):2062-72. https://doi.org/10.1016/j.jacc.2019.02.031. 
16. Dohrn IM, Sjostrom M, Kwak L, et al. Accelerometer-measured sedentary time and physical activity-A 15 year follow-up of mortality in a Swedish population-based cohort [J]. J Sci Med Sport. 2018;21(7):702-7. https:// doi.org/10.1016/j.jsams.2017.10.035.

17. Evenson KR, Wen F, Herring AH. Associations of Accelerometry-Assessed and Self-Reported Physical Activity and sedentary time With All-Cause and Cardiovascular Mortality Among US Adults. Am J Epidemiol. 2016;184(9):621-32. https://doi.org/10.1093/aje/kww070 Epub 2016 Oct 19. Erratum in: Am J Epidemiol. 2017 Jul 1;186(1):129. PMID: 27760774; PMCID: PMC5100839.

18. Tu QY, Qin Y, Wang JQ, Chen C, Ding GL, Xiang QY. Associations of sedentary times with incidence and risk factor clustering of cardiovascular diseases among adult residents in Jiangsu province: a follow-up study. Chin J Public Health. 2020;36(2):165-9. https://doi.org/10.11847/zgggw s1126263.

19. Bellettiere J, LaMonte MJ, Evenson KR, Rillamas-Sun E, Kerr J, Lee IM, et al. sedentary time and cardiovascular disease in older women: The Objective Physical Activity and Cardiovascular Health (OPACH) Study. Circulation. 2019;139(8):1036-46. https://doi.org/10.1161/CIRCULATIO NAHA.118.035312 PMID: 31031411: PMCID: PMC6481298.

20. Borodulin K, Karki A, Laatikainen T, et al. Daily Sedentary Time and Risk of Cardiovascular Disease: The National FINRISK 2002 Study [J]. J Phys Act Health. 2015;12(7):904-8. https://doi.org/10.1123/jpah.2013-0364.

21. Garcia JM, Duran AT, Schwartz JE, Booth JN 3rd, Hooker SP, Willey JZ, et al. Types of sedentary time and risk of cardiovascular events and mortality in blacks: the jackson heart study. J Am Heart Assoc. 2019;8(13):e010406 https://doi.org/10.1161/JAHA.118.010406 Epub 2019 Jun 26. PMID: 31238767; PMCID: PMC6662345.

22. Cumming TB, Holliday E, Dunstan D, English C. Television Viewing Time and Stroke Risk: Australian Diabetes Obesity and Lifestyle Study (1999-2012). J Stroke Cerebrovasc Dis. 2019;28(4):963-70. https://doi. org/10.1016/j.jstrokecerebrovasdis.2018.12.020 Epub 2019 Jan 22. PMID: 30683493.

23. McDonnell MN, Hillier SL, Judd SE, Yuan Y, Hooker SP, Howard VJ. Association between television viewing time and risk of incident stroke in a general population: Results from the REGARDS study. Prev Med. 2016;87:1-5. https://doi.org/10.1016/j.ypmed.2016.02.013 Epub 2016 Feb 13. PMID: 26879810; PMCID: PMC4884524.

24. Grace MS, Lynch BM, Dillon F, Barr EL, Owen N, Dunstan DW. Joint associations of smoking and television viewing time on cancer and cardiovascular disease mortality. Int J Cancer. 2017;140(7):1538-44. https://doi.org/ 10.1002/ijc.30580 Epub 2017 Jan 6. PMID: 28006837.

25. Ikehara S, Iso H, Wada Y, Tanabe N, Watanabe Y, Kikuchi S, et al. Television viewing time and mortality from stroke and coronary artery disease among Japanese men and women -- the Japan Collaborative Cohort Study. Circ J. 2015;79(11):2389-95. https://doi.org/10.1253/circj.CJ-141335 Epub 2015 Sep 7. PMID: 26346284.

26. Patel AV, Maliniak ML, Rees-Punia E, Matthews CE, Gapstur SM. Prolonged Leisure Time Spent Sitting in Relation to Cause-Specific Mortality in a Large US Cohort. Am J Epidemiol. 2018;187(10):2151-8. https://doi.org/ 10.1093/aje/kwy125 PMID: 29947736; PMCID: PMC6454412.

27. Engelen, L., Gale, J., Chau, J. Y., Hardy, L. L., Mackey, M., Johnson, N.,... Bauman, A. Who is at risk of chronic disease? Associations between risk profiles of physical activity, sitting and cardio-metabolic disease in Australian adults. Australian New Zealand J Public Health 2017, 41(2), 178-183. doi: https://doi.org/10.1111/1753-6405.12627.

28. Moller SV, Hannerz H, Hansen AM, Burr H, Holtermann A. Multi-wave cohort study of sedentary work and risk of ischemic heart disease. Scand J Work Environ Health. 2016;42(1):43-51. https://doi.org/10.5271/sjweh. 3540.

29. Bianchi VE, Ribisl PM. Reactive Oxygen Species Response to Exercise Training and Weight Loss in Sedentary Overweight and Obese Female Adults. J Cardiopulm Rehabil Prev. 2015;35(4):263-7. https://doi.org/10. 1097/HCR.0000000000000114 PMID: 25806958.

30. Carter S, Hartman Y, Holder S, Thijssen DH, Hopkins ND. sedentary time and Cardiovascular Disease Risk: Mediating Mechanisms. Exerc Sport Sci Rev. 2017;45(2):80-6. https://doi.org/10.1249/JES.0000000000000106 PMID: 28118158.

31. Wang M, Song Y, Baker JS, Fekete G, Gu Y. Sitting to standing postural changes: Energy expenditure and a possible mechanism to alleviate sedentary time. Physiol Int. 2018;105(2):157-65. https://doi.org/10.1556/ 2060.105.2018.2.14 PMID: 29975127.

32. Thorp AA, McNaughton SA, Owen N, Dunstan DW. Independent and joint associations of TV viewing time and snack food consumption with the metabolic syndrome and its components; a cross-sectional study in Australian adults. Int J Behav Nutr Phys Act. 2013;9(10):96. https://doi.org/ 10.1186/1479-5868-10-96 PMID: 23927043; PMCID: PMC3751141.

33. Karol S, Robertson MM. Implications of sit-stand and active workstations to counteract the adverse effects of sedentary work: A comprehensive review. Work. 2015;52(2):255-67. https://doi.org/10.3233/WOR-152168 PMID: 26444941.

34. Shrestha N, Kukkonen-Harjula KT, Verbeek JH, ljaz S, Hermans V, Pedisic Z. Workplace interventions for reducing sitting at work. Cochrane Database Syst Rev. 2018;6(6):CD010912. https://doi.org/10.1002/14651 858.CD010912.pub4 Update in: Cochrane Database Syst Rev. 2018 Dec 17;12:CD010912. PMID: 29926475; PMCID: PMC6513236.

\section{Publisher's Note}

Springer Nature remains neutral with regard to jurisdictional claims in published maps and institutional affiliations.

Ready to submit your research? Choose BMC and benefit from:

- fast, convenient online submission

- thorough peer review by experienced researchers in your field

- rapid publication on acceptance

- support for research data, including large and complex data types

- gold Open Access which fosters wider collaboration and increased citations

- maximum visibility for your research: over 100M website views per year

At BMC, research is always in progress.

Learn more biomedcentral.com/submissions 